The cuanthol-aniline as finally purified is a reddish-colored mobile liquid, having an agreeable ethereal odor, which resembles neither aniline or cenanthol. Its analys:s yielded $\mathrm{C} 75.10$ per cent., H 10.28 per cent., corresponding to the formula,

$$
\begin{aligned}
& \mathrm{C}_{13} \mathrm{H}_{2} \mathrm{NO}=\mathrm{C}_{6} \mathrm{H}_{7} \mathrm{~N}_{5} \mathrm{H}_{14} \mathrm{O}, \mathrm{in} \text { which } \\
& \mathrm{C}^{2} \text { is } 5.36 \text { per cent., and } \mathrm{H}^{2} 10.14 \text { per cent. }
\end{aligned}
$$

The cnanthol-xylidine closely resembles cenanthol-aniline in a 1pearance and smell. Its formula was found to be

$$
\begin{aligned}
& \mathrm{C}_{15} \mathrm{H}_{23} \mathrm{NO}=\mathrm{C}_{8} \mathrm{H}_{11} \mathrm{NC}_{2}, \mathrm{II}_{14} \mathrm{O} \text {. } \\
& \text { Found. } \\
& \text { C........ } 0.94 \quad \% 6.59 \\
& \text { H. . . . . } 10.00 \quad 10.64 \\
& \text { N....... } 5.93 \quad 5.96
\end{aligned}
$$

The cunthol-naphthylamine resembles the two preceding compounds in its appearance and properties, but was still more pronounced in its ethereal odor, which resembled that of pineapple.

Its formula is $\mathrm{C}_{17} \mathrm{H}_{23} \mathrm{NO}=\mathrm{C}_{20} \mathrm{H}_{9} \mathrm{~N} \mathrm{C}_{7} \mathrm{H}_{14} \mathrm{O}$.

$$
\begin{aligned}
& \text { Found. Calculated. } \\
& \text { C . . ....79.03 per cent. } \\
& 79.38 \text { per cent. } \\
& \mathrm{H} \ldots \ldots \ldots \ldots .50 \text {. . } \\
& 8.95
\end{aligned}
$$

It will be noted that all these contpounds formed synthetically by the direct union of one molecule of cenanthol with one molecule of the aromatic base, no water being eliminated, have a correspondingly elerated heat of combination. They are stable bodies, and were capable of sublimation, with only partial decomposition. The sublimates were not crystalline, and were identical in physical and chemical properties with the original substances, yielding on analysis the same formula.

\title{
SOLID RESIDUE FROM THE DISTILLATION OF CASTOR OIL IN VACUO.
}

\section{By Albert R. Leeds.}

In making cenanthol from castor oil there is always left in the flask a highly elastic, sticky substance, which was first investigated by Staněk (Jour. Pr. Chem., Vol. 63, p. 138.) Although Staněk's results have rever been accepted as conclusive, yet no one has reinvestigated the nature of this body, for which reasons I was induced to make the following research. 
According to the recommendation of Krafft, Ber. Ber., Vol. x, p. 2034, the œnanthol was prepared by distilling castor oil in vacuo a pressure of abont $100 \mathrm{~m}$. m. keing maintained. The operation must be watched very closely towards the end, because the residue in the retort, as soon as all the cenanthol has been driven off, liber. ates a large amount of gas which causes the caoutchouc-like mass to swell enormously and to fill the whole flask. Therefore, as soon as the bubbles of gas begin to appear, the vacuum is instantly relieved and the lamp removed. The residue, on the liberation of the gas, changes from a comparatively thin liquid to a very viscid mass that finally, on cooling, has almost the consistency of caoutchouc. It conld not be entirely removed from the flask by mechanical means, and therefore, after as much as possible had been removed hy a spatula, the remainder was saponified either with aqueous or alcoholic potash.

The caoutchouc-like mass was thoronghly washed, first with alcohol and then with ether, in neither of which is it at all soluble. Before washing, the substance is sticky and elastic, but the ether and alcohol remove all traces of stickiness, and most of the elasticity disappears. Long standing has the same effect, but in a lesser degree. The original color of the substance is a brownishred, but after washing it becomes grayish-white with a very faint tinge of yellow. The analyses were made on the body thus purified.

In his analysis Staněk gives the formula $\mathrm{C}_{42} \mathrm{H}_{65} \mathrm{O}_{5}$ as calculated from $\mathrm{C} 7 \% .11$ per cent. $\mathrm{H} 10.7 \%$ per cent. and $\mathrm{O} 12.12$ per cent. The percentages as found by me were : $\mathrm{C} ; 6.47$ per cent. $\mathrm{H} 10.69$ per cent. and $O 12.84$ per cen

The caoutchouc-like body by long continued boiling with aqueous or alcoholic potash is completely saponified. All the residues obtained were saponified, the solutions filtered hot, and the filtrates decomposed by hydrochloric acid. The organic acid in combination with potash, after decomposition by a mineral acid, presents none of the characteristics of the original caoutchouc-like mass. On the contrary, it is an oily body lighter than water, and has a reddish-brown color. The oil is extremely soluble in alcohol and ether, and insoluble in water. It was purified for analysis by dissolving in ether, after repeatedly washing with hot water, filtering, evaporating off the ether and drying at $100^{\circ}$.

The purified oil on analysis gave : $C$ \%0.22 per cent, $H 11.04$ per cent. O 18.74 per cent. Staněk in his analysis of the same oil, prepared by a slightly different method, found $\mathrm{C} r 0.40$ per cent, II 
11.00 per cent, $O 18.60$ per cent, from which he deduces the formula $\mathrm{C}_{36} \mathrm{H}_{6 \times} \mathrm{O}_{7}$.

In the acid filtrate from the oil decomposed by hydrochloric acid, no glycerine could be found, but only a small amount of a resinous body which was not investigated. This result also corresponds with that obtained by stanck.

A considerable amount of the oil was subjected to fractional distillation. When heated, the oil turns black and is decomposed, yielding at ever.increasing temperatures a distillate of light and almost colorless oils that have a very pungent and peculiar though not a disagreeable odor. These oils come off at points ranging from $110^{\circ}$ to $250^{\circ}$. They were collected in thee separate portions, having boiling points from $110^{\circ} 150^{\circ} 160^{\circ} 200^{\circ}$ and above $200^{\circ}$. Each portion was distiller three times, and finally three were taken whose boiling points were $120^{\circ} 180^{\circ}$ and $220^{\circ} \mathrm{C}$.

Their analysis yielded:

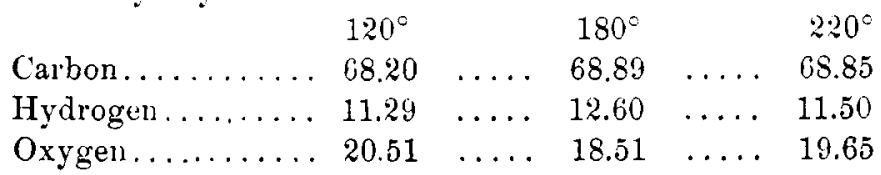

These oils do not form salts with potash or soda. On exposure to light and air they turn darker from absorption of oxygen.

Nitrogen was sought for in all of the oily products of the caoutchonc-like substance, but its presence in any could not be established.

The results above given do not bear out the views of Stanĕk with regard to the constitution of the caoutchouc body and its derivatives. Stanék assigns the formula $\mathrm{C}_{42} \mathrm{H}_{68} \mathrm{O}_{5}$ to the caoutchouc body, and terms it an Acryloxide compound consisting of his Pyroricinic Acid and Acrolein.

$$
\mathrm{C}_{42} \mathrm{H}_{68} \mathrm{O}_{5}=\mathrm{C}_{36} \mathrm{I}_{60} \mathrm{O}_{3}+\mathrm{C}_{8} \mathrm{H}_{8} \mathrm{O}_{2} \text {. }
$$

In this case the compound ought to contain Acrolein which it does not. No Acrolein could be detected either in the process of saponification or of distillation.

In the next place, the Pyroricinic Acid of Stanek which he regards as a fatty acid, although it has no analogies to any known series of fatty acids, is first formulated as $\mathrm{C}_{36} \mathrm{H}_{68} \mathrm{O}_{7}$. It was made by converting the oil obtained by saponification of the caoutchouc body, into a lead salt. But this body after keeping for three days at a temperature of $100^{\circ}$, became (according to Stančk). $\mathrm{C}_{38} \mathrm{H}_{68} \mathrm{O}_{2}$. He furthermore states that the water which thus came off did not 
exist in the original acid in the form of water, inasmuch as the correct formula of this acid should be regarded as $\mathrm{C}_{36} \mathrm{H}_{62} \mathrm{O}_{4}$.

I have not attempted to give rational formula for the caoutcho u body or for its oily distillates. I have merely given these resultsc the obtaining of which involved very considerable labor on $\mathrm{my}$, own part and that of my assistant Dr. Edgar Everhart, in the hope that some one will repeat the work with such large quantities of material as eventually to obtain by fractional distillation or otherwise, homogenous products.

\section{CRYPTIDINE.}

BY AIBBERT R. LEEDS.

When xylidine-acrolein, prepared as stated in a preceding article was subjected to dry distillation some oily drops of peculiar smell were given off. A considerable amount of this substance, therefore, after careful purification was thoroughly dried at a tempera. ture of $110^{\circ}$ and finely pulverized. Small portions of about 20 grms. each were introduced into a small tubulated retort, placed in an air-bath and subjected to distillation, carried on very slowly to avoid carbonization: No record could be taken of the temperature of the distillation since it exceeded $360^{\circ}$. At first, before decomposition set in, a small amount of water came over which was of a slightly acid reaction, and which was rejected. When the temperature rose higher and decomposition began, a distillate composed of oily drops mixed with water of an alkaline reaction, came over. The residue in the retort consisted of a porous carbonaceous nass, extremely difficult of combustion. The alkalinity of the distillate, was due to free ammonia given off in considerable quantities during the operation, the retort at the end being filled with its fumes.

About 155 grms. of the xylidine-acrolein were thus distilled in small portions at a time and the distillates collected. The water was separated from the oil by filtering through a wet filter, and heated for several hours at a temperature of $100^{\circ}$ till the weight was constant. The yield from 155 grms. of the xylidine-acrolein was 11 grms., or a little over 7 per cent.

Several unsuccessful attempts were made to purify the distillate, but no constant boiling point could be obtained. A small amount 